\title{
PRODUCTION OF TUMORS IN THE ABSENCE OF PARASITES *
}

\author{
ERWIN F. SMITH, Sc.D.
}

Pathologist in Charge, Laboratory of Plant Pathology, Bureau of Plant Industry, U. S. Department of Agriculture

WASHINGTON, D. C.

VARIETIES OF TUMORS IN PLANTS

There are many kinds of tumors in plants. These are due to a variety of causes which are principally living things-gall flies, plant lice, nematodes, fungi, myxomycetes and bacteria. Tumors may also be due to frost (Harvey), to mechanical irritation (Wolf) and, as I hope to convince you, to a lack of aëration and the resulting increase in acidity of the imperfectly aërated tissues. Clinically, if we may use such a term in speaking of plants, the tumors are either benign or malignant, sometimes grading from one into the other, as in crown gall. Morphologically, they are almost as diverse in appearance as the causes that produce them. Their general structure depends not only on the stimulus received from the parasite, but also on a variety of internal conditions peculiar to the host plant. In other words, the response of the plant varies not only according to the quantity and the quality of the stimulus received, but also according to the age of the plant, the parts attacked, the conditions of nutrition, and various unknown factors, which leads on the one hand to resistance and on the other to increased susceptitbility. The cells composing these tumors may be slow growing and nearly normal in size and orientation as in benign animal tumors, or the tumor may consist of a congeries of small, rapidly dividing, deep staining, disoriented, destructive, anaplastic cells, strongly suggestive of the malignant tumor cells of animals. Every tumor, of course, has its stroma, variable in amount.

What form the tumor takes depends partly on its location; but to a much greater extent on whether the parasites are few or many, whether they are imprisoned in small chambers, as in the case of gallfly larvae, or are free to move about in the tissue, as in the case of nematodes and bacteria. In the first case, the tumor tissue although hyperplasial approximates the normal tissue in form and arrangement of its cells, because the physical-chemical stimulus always proceeds in the same general direction, i. e., from a central cavity in all direc-

* Read before the Section on Dermatology and Syphilology at the SeventyFirst Annual Session of the American Medical Association, New Orleans, April, 1920. 
tions toward the periphery; there is, therefore, nothing to lead to disturbed growth and disorientation of cells. On the contrary, in a nematode or bacterial tumor the organisms are able to move about more or less and the chemical-physical stimulus proceeds sometimes from one direction and sometimes from another, leading to a frequently changed direction of growth and to much disorientation of cells. All tumors, so far as they are due to parasites, must be assumed to be due to the chemical-physical action of the by-products of the metabolism of these parasites, just as most communicable diseases are due not to the parasites themselves, but to their toxins. In case of crown gall, therefore, I cannot be properly accused of abandoning my first position, because I have undertaken to show that the parasite acts through its excretions. Diverse as are the tumors of plants due to parasites, I believe that the fundamental chemical-physical phenomena underlying them are much alike, and that the differences we see, when these differences are not due wholly to varying tissue reactions, must result simply from variations in volume, and direction and continuity of the chemical-physical stimulus. This must be true also of the nonparasitic tumors, and eventually $I$ hope to be able to formulate simple general laws applying to all of them.

\section{EXPERIMENTAL TUMORS IN PLANTS}

This paper relates to the experimental production of small benign tumors. It would be of no special interest if it had not grown out of crown-gall studies and did not appear to throw some light on the general phenomena of tumor formation. I have been experimentally interested in crown gall for fifteen years. For those who do not know what has been done, I summarize the leading discoveries made during this time:

In the Department of Agriculture a widely distributed, harmful plant tumor has been demonstrated to be due to a schizomycete. Although no bacteria are demonstrable in sections of this tumor, nevertheless, they are present in it and can be isolated from it by using the methods of the bacteriologist. By pure culture inoculations with the organism, the tumor can be reproduced at will and has been so reproduced hundreds of times. It may also be reproduced by grafting portions on suitable parts of healthy plants. This tumor possesses the power of continuous growth through several generations (Jensen). It is a hyperplasia which often grows rapidly. It contains few or many vessels, depending on whether the inoculated infected tissues are themselves feebly or highly vascular. Often it is imperfectly vascularized and decays early with the production of open wounds which proliferate from their edges. The tumor destroys by crushing or by 
invasion. It often develops invasive tumor strands on which are formed secondary tumors which show the structure of the primary tumor. If inoculations are made in the vicinity of groups of totipotent cells (root, shoot or flower rudiments), the tumor which develops is an embryoma, i. e., it is a rapidly developing, disoriented, anaplastic tissue containing dwarfed fragments of various organs having normal cell orientation, but not necessarily normal organ position-they may be upside down in the tumor. Such fragments may also come to the surface or be borne on the surface and grow for a time as dwarfed shoots or other organs which in turn may be invaded by the tumor tissues. Like cancer, if taken early, the tumor may be removed completely; but in later stages of growth it often returns after removal.

The parasite causing this tumor produces ammonia, aldehyd and various acids, and with these substances $I$ have succeeded in causing small hyperplasias in the absence of the parasite; I therefore assume that it is the by-products of the parasite liberated in the tissues which stimulate the normal cells to become tumor cells. These by-productsammonia, acetic acid, formic acid, etc.-act, I think, by causing cell precipitates which upset respiration and compel the affected cells to rearrange their protoplasm and divide at once or perish. We must suppose that these substances are given off by the bacteria continuously in minute quantities sufficient to stimulate the cells but not enough to kili them.

Following out my theory that disturbed cell respiration is at the bottom of tumor formation, I tried last year to find what results I could obtain in the absence of parasites by limiting the intake of air in various ways, and in each experiment I reached the same resultincreased acidity of tissues and the production of small hyperplasias.

I first experimented on the flesh of potato tubers, cutting out rectangular blocks under sterile conditions and hermetically sealing them in test tubes, the blocks resting on wet cotton. The tissues, being alive, continued to absorb water and to respire and transpire. They formed a cork layer over their cut surface and under this layer, as respiration and transpiration became increasingly difficult owing to the saturation of the air and its limited oxygen content, hyperplasias developed, rupturing to the surface. Titrations showed an increased acidity of the tissues. Sometimes these blocks of raw potato flesh developed shoots and roots which soon showed results of asphyxiation and these also bore many small hyperplasias. The tumors themselves rarely developed roots or shoots. Some of the tubes were kept in the dark at room temperature, and others were exposed in bright light to hothouse temperature, but the results were the same. I have been able to obtain in this way only small tumors, since in my potato blocks in sealed tubes the food supply is limited and the air soon exhausted; but 
by placing the potato flesh under better growing conditions with occasional renewal of the air, I believe it might be possible to induce the tumors to grow for a considerable period and perhaps to double or treble the size of any I have yet obtained. All of the tubes contained an abundance of water and the air was always saturated.

I obtained the same results, however, from whole tubers lying either in a covered pasteboard box in dry air on my laboratory table, or exposed to the light on the same table in a large open jar. The tubers pushed sprouts, but owing to lack of water these could not develop organs of respiration and transpiration (that is, leaves), and they became much thickened and covered with numerous small hyperplasias, located under wide open stomata. The tissues developing these hyperplasias were gorged with sugar and starch, contained more oxidizing enzymes than normal, and on titration proved to be several times as acid as normal shoots and tubers. Here again I think imperfect respiration led to increased acidity of the tissues and to the development of the tumors.

In a third series of experiments I obtained numerous small tumors from green potato stems in active growth by suddenly destroying the leafy tops, i. e., the respiring and transpiring organs. This immediately stopped the upward movement of a large quantity of aërated water; oxygen hunger and acidity developed and hyperplasias resulted.

Finally, I have repeatedly obtained the same results on the stems of a variety of plants by blocking the lenticels, which are aërating organs (organs both of respiration and transpiration), with Squibb's liquid petrolatum, following the petrolatum experiments of Wisniewski and of Schilling. As soon as the exchange of gases is interfered with, viz., the intake of air and the movement of aerrated water to the surface, tumors begin to form under these lenticels.

In crown gall and various other tumors due to parasites the parasite furnishes the acids and other stimuli as a direct result of its metabolism, but the small benign tumors I am describing are not the result of parasitism. The increased acidity probably results from the incomplete combustion of carbohydrates, i. e., from anaërobic cellrespiration due to poor circulation and imperfect aëration, which we know to be a peculiarity of tumors in general, since most of them are poorly vascularized and out of the general circulation.

If, for any reason, conditions such as I have outlined should occur in parts of the animal body, I should expect to see similar phenomena arise in such parts and, the nutrition being more abundant, the tumors might become large. But as most tumors in plants, and especially in the more destructive ones, are the direct result of parasitism, parasites should also be looked for as the cause of rapidly growing, malignant animal tumors. We are forced to the belief that they must be of 
parasitic origin unless we are to regard plants and animals as so unlike that no conclusions drawn from the one can be made to apply to the other. Modern biology opposes such an iclea. Those who are interested will find this subject treated in more detail with numerous illustrations in my textlook on "Bacterial Diseases of Plants." "

\section{SLMMARY}

I have produced hyperplasias (1) by the direct application of dilute acids and alkalies to susceptible plant tissues: (2) by the introduction into the tissues of certain foreign organisms (especially the crown gall bacterium which produces acids and alkali in flask cultures and probably also inside the cells as a result of its metabolism), and (3) I can now bring alout the same results in the absence of parasites and their products by limiting the intake of oxygen, thus compelling the cells themselves to manufacture the stimulus which leads to the (levelopment of hyperplasias. I can conceive of this taking place only as the result of an anaërobic cell respiration acting on the youngest, most active cells of a tissue: but there must be always some oxygen of the air present, otherwise there will be complete asphyxiation of the tissues. as happened in my first experiments. I'robably overgrowths due to freezing and to mechanical injuries will also be found to depend on local interference with cell respiration.

The most striking tumors are obtained by inoculatitng the crown gall organism, Bactcrium tumcfacicns. Some of these are simple tumors and others are tumors containing roots and shoots. Some also show the beginning of secondary tumors, and in the embryomas the invasion of tumor tissue into the embryomatous parts (young roots and shoots).

1. Smith, E. F.: Crown Gall of Plants and Cancer, Science 43:348 (June 23) 1916.

2. Smith, Erwin F.: Bacterial 1)iseases of Plants, Philadlelphia. IV. B. Saunders Company: in press. 